\title{
DIURNAL VARIATION IN THE URINARY EXCRETION OF NEUTRAL LIPID-SOLUBLE REDUCING STEROIDS IN CONGESTIVE CARDIAC FAILURE AND CIRRHOSIS OF THE LIVER WITH ASCITES ${ }^{1,2}$
}

\author{
By RALPH GOLDMAN AND SAMUEL H. BASSETT \\ (From the Metabolic Unit, General Medical Research Program, Veterans Administration \\ Center, Los Angeles, and the Department of Medicine, University of California, \\ Los Angeles, California)
}

(Submitted for publication September 24, 1951; accepted December 17, 1951)

Pincus and his collaborators (1-4) have demonstrated that there is a normal cycle of excretion of neutral, lipid-soluble reducing steroids which has a maximum between 7 a.m. and 11 a.m., decreases during the afternoon, and is at a minimum during the night. This corresponds to the normal excretory cycle of other urinary constituents (5-13). It has also been shown that in congestive cardiac failure $(14,15)$ and in cirrhosis of the liver with ascites (16) there is a reversed diurnal cycle of water and sodium excretion, with maximum values during the night in a high proportion of the individuals studied. This investi-

1 Reviewed by the Veterans Administration and published with the approval of the Chief Medical Director. The statements and conclusions of the authors are the results of their own study and do not necessarily reflect the opinion or policy of the Veterans Administration.

2 This investigation was supported (in part) by a research grant from the National Heart Institute, of the National Institutes of Health, Public Health Service. gation was designed to determine if the excretion of steroids was also altered by these conditions.

\section{MATERIAL AND METHODS}

Ten normal male adults were used as controls. Fourteen male patients with congestive heart failure, of various etiologies and in differing degrees of decompensation, and 12 male patients with cirrhosis of the liver and ascites comprised the abnormal groups. Almost all of the patients were on a standard hospital diet containing a calculated 1,000 milligrams of sodium daily. Diuretics were not used within $\mathbf{4 8}$ hours of the urine collection periods, and no clinical evidence of urinary obstruction was present. Three consecutive, eight-hour, spontaneously voided urine specimens were collected from each individual. The one collected between 6 a.m. and 2 p.m. was designated the morning specimen, the one collected between 2 p.m. and 10 p.m. was designated the afternoon specimen, and the one collected between 10 p.m. and 6 a.m. was designated the night specimen. The time of the night specimen was chosen so that it would coincide most closely with the hours of sleep. The volume of each urine was measured and the quantity of neutral

TABLE I

Normal subjects

\begin{tabular}{|c|c|c|c|c|c|c|c|c|c|c|}
\hline \multirow{2}{*}{ Pt. } & \multirow{2}{*}{ Age } & \multirow{2}{*}{ Date } & \multicolumn{4}{|c|}{ Steroids* } & \multicolumn{4}{|c|}{ Water } \\
\hline & & & Total & Morning & Afternoon & Night & Total & Morning & Afternoon & Night \\
\hline $\begin{array}{l}\text { C. D. } \\
\text { W. A. } \\
\text { S. B. } \\
\text { E. M. } \\
\text { W. M. } \\
\text { R. G. } \\
\text { W. F. } \\
\text { G. M. } \\
\text { M. L. } \\
\text { W. B. } \\
\text { Standard } \\
\text { Mean }\end{array}$ & \begin{tabular}{|c|c}
30 \\
31 \\
54 \\
30 \\
30 \\
31 \\
29 \\
60 \\
30 \\
30 \\
leviation
\end{tabular} & $\begin{array}{l}\text { Feb. '51 } \\
\text { Feb. '51 } \\
\text { Mar. '51 } \\
\text { Mar. '51 } \\
\text { Mar. '51 } \\
\text { Sept. '50 } \\
\text { Sept. '50 } \\
\text { Apr. '51 } \\
\text { Mar. '51 } \\
\text { May '51 }\end{array}$ & $\begin{array}{l}\text { mg. } \\
2.95 \\
3.25 \\
3.23 \\
3.43 \\
2.62 \\
2.51 \\
2.60 \\
2.63 \\
4.35 \\
2.47 \\
0.59 \\
3.00\end{array}$ & $\begin{array}{c}\% \\
52 \\
45 \\
38 \\
45 \\
39 \\
40 \\
50 \\
38 \\
37 \\
35 \\
5.8 \\
42\end{array}$ & $\begin{array}{c}\% \\
22 \\
25 \\
37 \\
29 \\
30 \\
29 \\
30 \\
33 \\
33 \\
35 \\
4.5 \\
30\end{array}$ & $\begin{array}{c}\% \\
26 \\
30 \\
25 \\
26 \\
31 \\
31 \\
20 \\
29 \\
30 \\
30 \\
3.5 \\
28\end{array}$ & $\begin{array}{c}m l . \\
1,165 \\
1,550 \\
1,190 \\
1,070 \\
1,425 \\
1,822 \\
1,230 \\
1,065 \\
1,370 \\
1,153 \\
240 \\
1,304\end{array}$ & $\begin{array}{l}\% \\
54 \\
61 \\
45 \\
65 \\
50 \\
37 \\
54 \\
40 \\
33 \\
40 \\
10.6 \\
48\end{array}$ & $\begin{array}{c}\% \\
14 \\
16 \\
34 \\
20 \\
19 \\
30 \\
32 \\
30 \\
31 \\
30 \\
7.5 \\
26\end{array}$ & $\begin{array}{c}\% \\
32 \\
23 \\
21 \\
15 \\
31 \\
33 \\
14 \\
30 \\
36 \\
30 \\
7.7 \\
26\end{array}$ \\
\hline
\end{tabular}

* Neutral lipid-soluble reducing steroids.

Boldface value for mean indicates that difference from mean night value exceeds 0.05 level of confidence. 


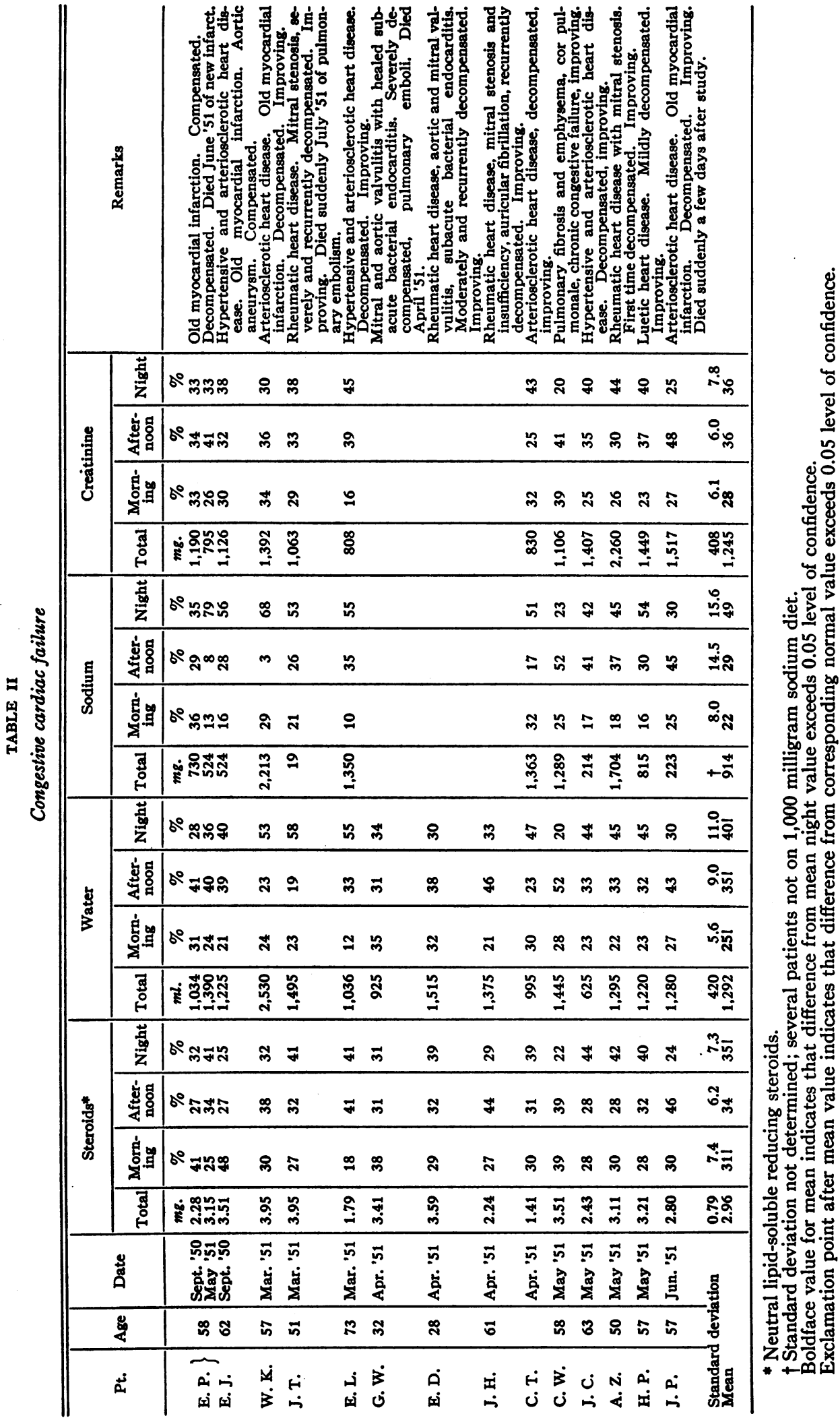




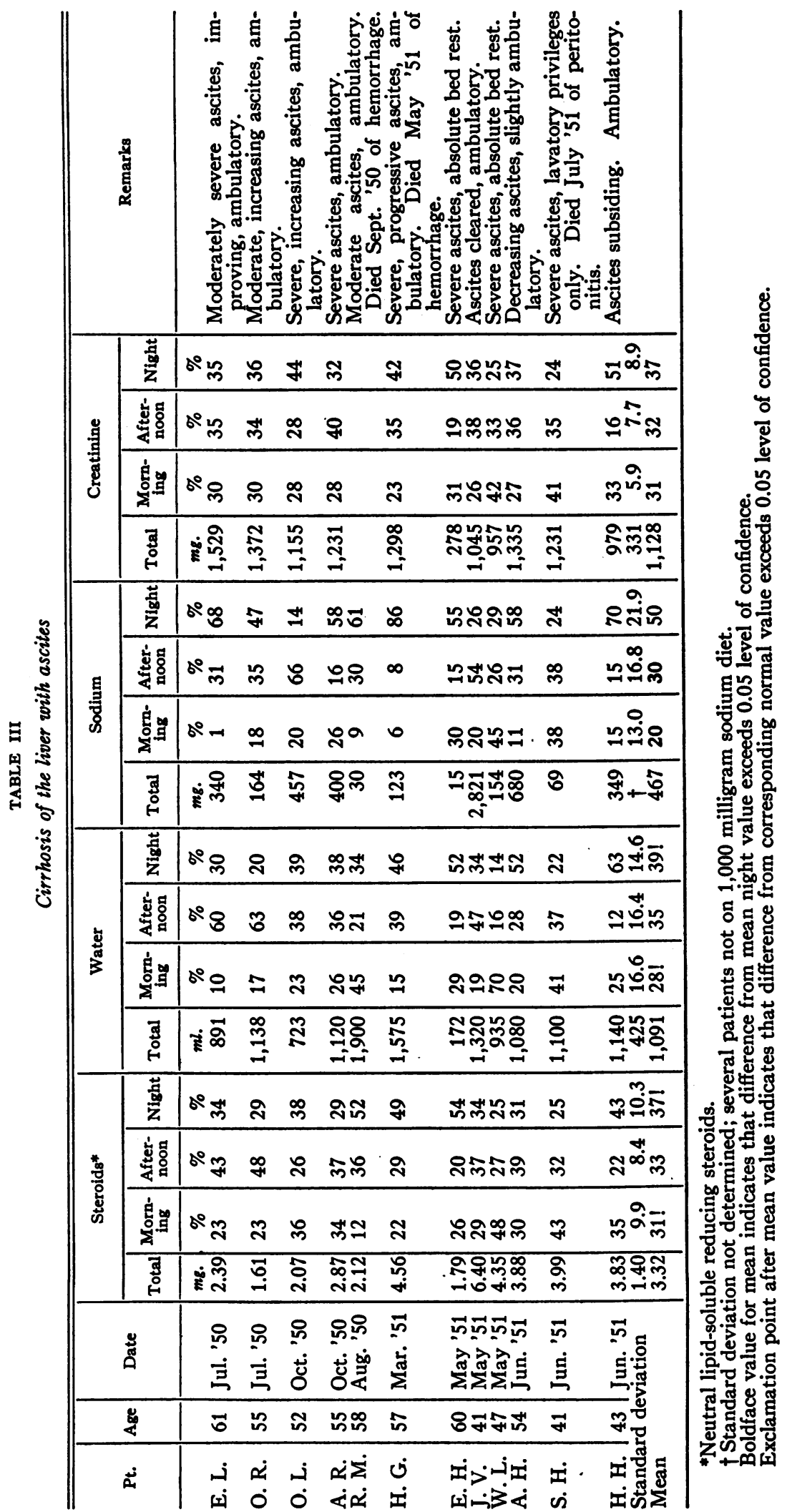


lipid-soluble reducing steroids ${ }^{8}$ determined by the method of Heard, Sobel and Venning (17). In almost all of the specimens obtained from the cardiac and cirrhotic patients, the quantity of excreted sodium was determined by means of the Beckman flame photometer and the quantity of excreted creatinine was determined by the Bonsnes and Taussky (18) modification of the Jaffe reaction.

\section{RESULTS}

The tables summarize the clinical data and the results. The total amount of the excreted substance is indicated in the first column of each group, and the succeeding three columns indicate the amount excreted in the morning, afternoon and night periods, respectively, expressed as per cent of the total amount excreted.

Table I indicates the results obtained in the normal subjects. All demonstrated a morning maximum steroid excretion, and most had a morning maximum water excretion. The average 24hour excretion of steroids was 3.00 milligrams.

The pattern of excretion of steroids, water, sodium and creatinine in 14 patients with congestive cardiac failure is seen in Table II. The average 24-hour excretion of steroids was 2.96 milligrams, which was remarkably close to the normal value. However, the distribution of the excreted steroids showed a definite alteration: in only four studies was the maximum excretion in the morning, and in two of these, the patients (E. P. and E. J.) were very well compensated by intensive therapy. The steroid pattern resembled the excretory cycles of the water, sodium and creatinine. It can be seen that the fluctuations in excretion of steroids, water and creatinine from period to period are of the same order, but that excretion of sodium shows more marked variations.

The observations made on 12 patients with cirrhosis of the liver and ascites are seen in Table III. The results compare closely to those of the cardiac group. The average 24-hour excretion of steroids, 3.32 milligrams, is slightly higher than for the other two groups. However, these differences are not statistically significant. It can be seen that the excretory cycle is abnormal in most instances, that the fluctuation in the water, creatinine and steroid cycles is less than normal, while fluctuation in the sodium cycle is proportionately greater, and that most of the variations in excretion of the

8 Hereafter referred to as steroids. observed substances from period to period are in the same direction. Despite the apparent trend, the differences in the creatinine values are not significant, and cannot be interpreted to demonstrate a nocturnal increase in the glomerular filtration rate.

\section{DISCUSSION}

Most studies on diurnal variation in urinary excretion have concerned the normal patterns. These patterns have been well documented, and there is general agreement among investigators that the maximum output of water, sodium, potassium, chloride, urea and creatinine is during the day, with a peak either just before or just after noon (5-13). Recently, a number of studies on abnormal variations have appeared, especially pertaining to the nocturnal diuresis found in patients with congestive cardiac failure $(14,15)$. We have recently shown that there is a similar nocturnal diuresis in cirrhosis of the liver with ascites (16). Although a nocturnal increase in renal plasma flow has been demonstrated in congestive cardiac failure $(14,15)$, which is associated with an increased glomerular filtration rate, this does not necessarily explain' the entire mechanism of the nocturia. To our knowledge no similar studies of renal plasma flow and glomerular filtration rate have been performed on patients with cirrhosis of the liver. In both of these conditions a nocturnal diuresis of water and sodium has been observed, but in our series (16) most of the patients exhibited no consistent associated diuresis of potassium.

The work of Pincus and his collaborators demonstrated that normally there was a maximum excretion of steroids during the morning, a decreased excretion during the rest of the day, and a minimum during the night. They believed that the morning increase was not due to increased filtration alone, since the excretion of steroids showed a greater proportionate increase than did the excretion of creatinine. The variation was considered to be the result of the increased stress due to resumption of activity after sleep. They noted that specific stress situations were associated with an increase in adrenal cortical steroid excretion occurring within a short time following the application of the stress. 
The present studies confirm the nature of the steroid excretory cycle in normal individuals. However, there is a fairly consistent relationship between the excretion of steroids, water and creatinine, suggesting that there may be a similar excretory mechanism for each, and that under these conditions excretion may be related to the filtration rate. A similar relationship is seen in congestive failure and cirrhosis, although there is displacement in the time of peak excretion. This shift in the cycle cannot be attributed to periods of excessive stress, first because the total steroid excretion is no greater than in the normals, and second because there is no evidence of an altered stress cycle. It may be suggested that in some of the patients with congestive cardiac failure nocturnal episodes of paroxysmal dyspnea and insomnia may be related to increased stress; however, patients who slept soundly during the collection period also demonstrated increased nocturnal steroid excretion. None of the patients with cirrhosis showed evidence of disturbed sleep other than that caused by the inconvenience of the nocturia itself. It is apparent either that more steroids are being presented to the kidney during the night, or that the kidney is relatively more efficient in excreting the steroids at that time.

From the data it appears that the amount of steroid excreted in 24 hours is relatively constant, and that the values for patients with congestive cardiac failure and cirrhosis of the liver are not significantly different from the normals. Abnormal patterns of diurnal urinary excretion of water, sodium, and creatinine are associated with similarly abnormal patterns of steroid excretion. It does not seem possible to determine from the data whether this abnormal excretory pattern for water, sodium and creatinine results from the pattern of steroid excretion, or whether the rate of steroid excretion is itself governed by the same alternate factors. In addition to the absence of evidence of increased adrenocortical activity, there was no evidence of an alteration in the stress cycle of these patients. Gaunt, Birnie and Eversole (19) have reviewed data demonstrating that an adequate amount of cortical hormone is necessary for water diuresis. However, they point out that at the same time as there is increased cortico-steroid there is usually an increased retention of sodium. While this may be true on an overall balance, fluc- tuations in sodium excretion during the day are in the same direction as fluctuations in steroid excretion, rather than in the opposite direction as would be expected.

\section{CONCLUSIONS}

1. The average 24-hour excretion of neutral lipid-soluble reducing steroids was 3.00 milligrams in ten normal adults, 2.96 milligrams in 14 patients with decompensated or recompensated cardiac failure, and 3.32 milligrams in 12 patients with cirrhosis of the liver and ascites.

2. In all of the normal controls there was a significant morning maximum excretion of steroids. In both of the abnormal conditions studied the period of maximum excretion was most commonly observed in the afternoon or during the night.

3 . With few exceptions, the excretion of steroids in cardiac failure and cirrhosis was proportional to the excretion of creatinine within the limits of error of the methods. This suggests that the excretion of steroids may be proportional to the glomerular filtration rate.

4. Since the total steroid excretion is within normal range, there is no evidence of increased or abnormal stress as a cause of the abnormal steroid excretory pattern. It is possible that the glomerular filtration rate is proportional to adrenocortical activity as measured by steroid excretion. However, it seems more probable that the urinary content of the steroid is proportional to the excretory rate.

5. In the normal and abnormal states studied, the water excretion generally paralleled that of creatinine and steroids, while the sodium excretion showed more marked variations, usually, but not invariably, in the same direction.

\section{ACKNOWLEDGMENT}

We wish to express our thanks to Miss Lucy Birzis, Mrs. L. Robert Bennett and Miss Tomoko Fukui for their technical assistance.

\section{REFERENCES}

1. Pincus, G., A diurnal rhythm in the excretion of urinary ketosteroids by young men. J. Clin. Endocrinol., 1943, 3, 195.

2. Pincus, G., Studies of the role of the adrenal cortex in the stress of human subjects. Recent Progr. Hormone Research, 1947, 1, 123. 
3. Pincus, G., Romanoff, L. P., and Carlo, J., A diurnal rhythm in the excretion of neutral reducing lipids by man and its relation to 17-ketosteroid rhythm. J. Clin. Endocrinol., 1948, 8, 221.

4. Romanoff, L. P., Plager, J., and Pincus, G., The determination of adrenocortical steroids in human urine. Endocrinology, 1949, 45, 10.

5. Cathcart, E. P., Kennaway, E. L., and Leathes, J. B., On the origin of endogenous uric acid. Quart. J. Med., 1907-1908, 1, 416.

6. Gerritzen, F., The rhythmic function of the human liver. Acta med. Scand. Suppl., 1940, 108, 121.

7. Kleitman, N., Studies on the physiology of sleep. I. The effects of prolonged sleeplessness on man. Am. J. Physiol., 1923, 66, 67.

8. Kleitman, N., Sleep and Wakefulness as Alternating Phases in the Cycle of Existence. Univ. Chicago Press, Chicago, 1939.

9. MacKay, E. M., Studies of urea excretion. V. The diurnal variation of urea excretion in normal individuals and patients with Bright's disease. J. Clin. Invest., 1928, 6, 505.

10. Manchester, R. C., The diurnal rhythm in water and mineral exchange. J. Clin. Invest., 1933, 12, 995.

11. Simpson, G. E., Diurnal variation in the rate of urine excretion for two hour intervals: some associated factors. J. Biol. Chem., 1924, 59, 107.
12. Simpson, G. E., Changes in the composition of urine brought about by sleep and other factors. J. Biol. Chem., 1929, 84, 393.

13. Sirota, J. H., Baldwin, D. S., and Villarreal, H., Diurnal variations of renal function in man. $\mathrm{J}$. Clin. Invest., 1950, 29, 187.

14. Baldwin, D. S., Sirota, J. H., and Villarreal, H., Diurnal variations of renal function in congestive heart failure. Proc. Soc. Exper. Biol. \& Med., 1950, 74, 578.

15. Fejfar, Z., and Brod, J., The excretion of chlorides in patients with heart failure. Quart. J. Med., 1950, 19, 221.

16. Goldman, R., Studies in diurnal variation of water and electrolyte excretion: nocturnal diuresis of water and sodium in congestive cardiac failure and cirrhosis of the liver. J. Clin. Invest., 1951, 30, 1191.

17. Heard, R. D. H., Sobel, H., and Venning, E. H., The neutral lipide-soluble reducing substances of urine as an index of adrenal cortical function. J. Biol. Chem., 1946, 165, 699.

18. Bonsnes, R: W., and Taussky, H. H., On colorimetric determination of creatinine by the Jaffe reaction. J. Biol. Chem., 1945, 158, 581.

19. Gaunt, R., Birnie, J. H., and Eversole, W. J., Adrenal cortex and water metabolism. Physiol. Rev., 1949, 29, 281. 